Aletria, Belo Horizonte, v. 30, n. 3, p. 63-84, 2020

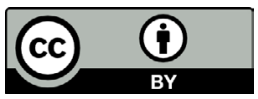

\title{
A espaldas de un gigante: Las traslaciones filmoliterarias brasileñas en el cine latinoamericano
}

\author{
Behind a Giant's Back: Brazilian Film-Literature \\ Translations in Latin American Cinema
}

\author{
David García-Reyes \\ Universidad de Concepción (UdeC), Concepción / Chile \\ mangarcia@udec.cl \\ http://orcid.org/0000-0003-3445-1304
}

Resumen: El estudio aborda una visión panorámica de las traslaciones filmoliterarias del cine brasileño y proyecta los espacios comunes en el que las tendencias del cine latinoamericano se inscriben junto a la enorme producción audiovisual del Brasil y el distanciamiento cultural del país con el resto de las repúblicas de América Latina. Esta aparente indiferencia estaría vinculada a lo idiomático. El cine brasileño en su posición como un cine escorado dentro de la periferia cultural de la región, ofrece valiosas lecciones al conjunto de Latinoamérica a lo largo de su historia. La producción de la literatura y el audiovisual nacional más que un alejamiento confirma la cercanía ideológica, temática, estética y cultural que configuran el cine de Brasil como una potente industria que ofrece algunos de los mejores ejemplos del cine latinoamericano de siempre.

Palabras claves: Cine brasileño; traslaciones filmoliterarias; cine latinoamericano; literatura y cine; cinema novo.

Abstract: The study presents a panoramic view of the film-literary translations of Brazilian cinema and describes trends in common with Latin American cinema. The audiovisual production of Brazil and the cultural distancing of the country with the rest of Latin America's republics shows an indifference related to language comprehension. Brazilian cinema, in its detached position within the cultural periphery of the region, offers valuable lessons in Latin American cinema. Brazilian literature and its film adaptations make up a powerful industry that, more than detachments, confirms 
ideological, thematic, aesthetic and cultural proximities, and offers some of the best examples of Latin American cinema ever.

Keywords: Brazilian cinema; film-literature translations; Latin American cinema; literature and cinema; cinema novo.

\section{Introducción y presentación del estudio}

El sorprendente y limitado correlato que se establece entre la cultura lusófona con el resto de las culturas latinoamericanas, y por extensión la conexión que se produce entre los productos culturales brasileños con los del resto de América Latina es exigua y adolece de una retroalimentación poco significativa, a excepción tal vez de los intercambios y permeabilidades musicales. Al margen de modelos de integración comercial sudamericana como el Mercosur y sin buscar culpables, se hace evidente que los países hispanohablantes de la región manifiestan una perenne indiferencia ante la producción literaria y cinematográfica de un gigante demográfico, que además supone un polo industrial a nivel editorial y audiovisual. Este distanciamiento cultural se podría explicar por la distancia lingüística y por los intereses de las distribuidoras de no acercar el cine brasileño al resto de la región, estrategia vinculada a los intereses de las grandes corporaciones de producción y exhibición, cercanas a las grandes corporaciones de producción y distribución mundial.

La visibilidad de la cultura brasileña ha contado con excepciones singulares con obras literarias y films que han dispuesto algunos éxitos importantes en las producciones culturales de Brasil, encarnados en la literatura por un factótum como Jorge Amado o el bestseller man Paulo Coelho. ${ }^{1}$ Como bien advierte Alberto Elena, en los años sesenta del siglo pasado el cinema novo se erigió en un aldabonazo de similares efectos que el cine cubano o los nuevos cines árabes (ELENA, 1999, p. 16-17). El reconocimiento e interés de la crítica de Europa y Estados Unidos por el cine brasileño ha estado signado por el auge de esos nuevos cines y posteriormente se ha instalado en los éxitos que, puntualmente, generaba la industria cinematográfica brasileña. Estos fenómenos cinematográficos, en la mayoría de los casos, retornaban a las pantallas de América Latina

\footnotetext{
${ }^{1}$ Contrastando con la reverenciada obra de Amado, las traslaciones de obras literarias de Coelho son bastante escasas y han tenido más eco en contadas producciones o proyectos de la industria audiovisual de Estados Unidos que el interés mostrado por parte del cine brasileño.
} 
impulsados por haber sido éxitos globales o por el reconocimiento crítico y los premios en un festival, e incluso por su impacto en los circuitos euro-norteamericanos, etc. Validando así el regreso de esos títulos a los espacios de vecindad de la región, que parecía estar mirando a otro lado. La tendencia ha podido cambiar tenuemente en la medida en la que han crecido las coproducciones entre Brasil y el resto de las industrias audiovisuales iberoamericanas.

Lo apuntado contrasta con la dimensión territorial de Brasil, que comparte fronteras con todas las repúblicas sudamericanas con las excepciones de Ecuador y Chile. La situación geográfica de Brasil es central dentro de Sudamérica, no se trata de una posición periférica dentro de la periferia, valga la redundancia, pero si es periférica, limítrofe y escorada la percepción que se tiene de las industrias culturales brasileñas dentro de América Latina. La negación o el desconocimiento de lo que hace el vecino no es infrecuente dentro del ámbito hispánico, sirvan de ejemplo las relaciones seculares entre España y Portugal o la distancia cultural existente de Brasil con vecinos como Venezuela o Colombia por citar dos casos. Por ello, resulta problemático pensar en la invisibilidad de una producción cultural tan abundante y rica como la brasileña. En cambio, Brasil si ha sido más proactivo en la búsqueda de una convergencia cultural con sus vecinos, tal y como manifiestan las políticas de inmersión lingüística que favorecen el español como la segunda lengua dentro del sistema escolar brasileño. ${ }^{2}$

A lo largo de más de 120 años de historia, el cine brasileño ha recurrido, como el resto de las cinematografías del mundo a nutrirse de las literaturas nacionales. Se da la circunstancia, como ocurrió en México o Argentina, que en un primer momento los cineastas acudieron a textos matriciales escritos y publicados en las que eran las antiguas metrópolis coloniales durante las primeras décadas del cine latinoamericano. Del mismo modo que Benito Pérez Galdós o Ramón María del Valle Inclán ofrecieron textos idóneos para su traslación en el agro mexicano o en las llanuras pampeanas, hay una serie de escritores portugueses como Camilo Castelo Branco, que estimularán un proceso análogo dentro de la naciente cinematografía brasileña. De esta manera, las tendencias comunes de los cines latinoamericanos también lo son en Brasil.

\footnotetext{
${ }^{2}$ La enseñanza y el conocimiento del español han sido materia obligatoria por ley (BRASIL, 2005) en la oferta curricular de los niveles primarios y medios de las escuelas brasileñas, aunque en 2017, el gobierno de Michel Temer revocó parte de dicha legislación.
} 
El estudio viene avalado por la necesidad de dimensionar y textualizar algunas de esas perspectivas comunes entre el audiovisual brasileño y las industrias del resto de América Latina. Para lo anterior, se toman los procesos de traslación filmoliterarias ${ }^{3}$ que se han sucedido a lo largo de la historia del cine brasileño, racionalizando una producción ingente que clarifica los caminos emprendidos por el cine latinoamericano en su conjunto y que vivieron una tímida confluencia a partir del Primer Festival de Nuevo Cine Latinoamericano y el Primer Encuentro de Cineastas Latinoamericanos (1967), celebrados conjuntamente en Viña del Mar (Chile), junto a la creación del militante Comité de Cineastas de América Latina (1974). La llegada de los distintos regímenes dictatoriales a lo largo de la década de 1970 abocaría a los nuevos cines a algo similar a un acta de defunción, negada por iniciativas como el Festival de La Habana (1979) que, tomando el testigo de la cita chilena, se convertiría en una reunión anual que ha permitido mostrar las producciones de cientos de creadores de la región. ${ }^{4}$

La industria audiovisual de Brasil conforma una de las grandes cinematografías del séptimo arte en América Latina, en clara correspondencia por producción y significación con los cines de México y Argentina. El uso de la lengua portuguesa vendría a condicionar una circulación y distribución regionales de los films brasileños menor que el de otras cinematografías, difuminando la relevancia de creadores y obras imprescindibles en el contexto regional. La recepción del cine brasileño es análoga al de las literaturas en lengua portuguesa, que, aunque merecen una consideración preeminente, tanto por la cantidad como por la calidad de propuestas a lo largo de su historia no se distribuyen en función de su vigor industrial o valores artísticos. El caso brasileño es el de un cine periférico y resulta una ironía, pues se trata del mayor mercado local de cine de América Latina. Brasil es el sexto país más poblado del planeta, sus potenciales espectadores exponen las enormes posibilidades industriales y comerciales del audiovisual nacional y son susceptibles de esperar también las propuestas de producciones continentales.

\footnotetext{
${ }^{3}$ En esta línea, la investigación asume su naturaleza comparatista y se posiciona junto a propuestas como la de Naiara Sales Araujo (2018).

${ }^{4}$ Otra cuestión de estudio sería la incidencia efectiva de las producciones brasileñas dentro de las distintas ediciones del festival cubano.
} 


\section{Las traslaciones filmoliterarias brasileñas: del cine silente a los films amadianos}

Las limitaciones del estudio quedan enmarcadas por los horizontes de las primeras décadas del audiovisual en las cinematografías apuntadas, vinculadas también a las dificultades económicas de la industria brasileña en consonancia con una dependencia de la financiación estatal genérica de los cines de Sudamérica, una circunstancia que ha marcado también al cine brasileño y su irregular desarrollo industrial.

Los pioneros del cine brasileño en la llamada Bela Época o en los primeros centros de producción regional durante los años veinte del siglo XX -Recife, Campinas o Cataguases-tomaron de la literatura portuguesa muchos de los argumentos que el cine silente nacional se encargaría de producir. No obstante, la notoria y creciente literatura brasileña se encargaría también de proveer historias al cine. La cinematografía brasileña del período contaría con importantes traslaciones filmoliterarias, algo que evidencian títulos como Amor de perdição (1914) de Francisco Santos, basado en la novela romántica (1862) del popular escritor portugués Camilo Castelo Branco. ${ }^{5}$ Producciones de marcado carácter literario como A viuvinha (1914) y Coração de gaúcho (1920), dirigidas por Luiz de Barros, a partir de las novelas $A$ viuvinha (1857) y O gaúcho (1870) de José de Alencar, autor del romanticismo brasileño. Alencar es uno de los escritores más adaptados del cine brasileño, como revelan los films de Vittorio Capellaro, ${ }^{6}$ pionero del cine brasileño de origen italiano, director de dos versiones de la novela indigenista $O$ Guarani (1857), estrenadas en 1916 y en 1926. La obra literaria de José de Alencar cuenta con más de una decena de adaptaciones y el propio Capellaro dirigiría Iracema (1917), basada en otra popular novela (1865) de Alencar.

\footnotetext{
${ }^{5}$ Novela que ha sido objeto de otras traslaciones al cine, entre ellas una segunda versión brasileña en el período silente dirigida por José Vianna y estrenada en 1918. Posteriormente, en Portugal, se produjo en 1921 el film homónimo del realizador francés George Pallu, el largometraje de 1943 de António Lopes Ribeiro, la serie de televisión brasileña de 1965, la miniserie portuguesa Amor de perdição: memórias d'uma familia (1978) de Manoel de Oliveira o la cinta portuguesa Um amor de perdição (Mário Barroso, 2008).

${ }^{6}$ Previamente, el cineasta italiano había estrenado Inocência (1915), inspirada en la novela (1872) del Visconde de Taunay, estableciendo la primera de las muchas adaptaciones del texto durante el siglo XX.
} 
En esta confluencia e interés por autores portugueses y brasileños, la etapa sonora del cine brasileño conocerá una perpetuación casi canónica de los autores explotados en el período silente. Asimismo, encontramos estrenos como Alma do Brasil (1931) de Líbero Luxardo, inspirada en la novela A Retirada da Laguna (1871) del Visconde de Taunay, Onde a terra acaba (1933) de Octavio Gabus Mendes trasladando el folletín Senhora (1874) de José de Alencar y Pureza (1940) de Chianca de Garcia, traslación de la novela del mismo título (1937) de José Lins do Rego, que marca un punto de inflexión e interés del cine brasileño por narradores contemporáneos, tendencia del audiovisual que compagina la literatura fundacional decimonónica de Brasil con los nuevos autores, inscritos en corrientes modernistas.

En consonancia con esta orientación contemporánea, la cultura brasileña encuentra a uno de sus más importantes artífices, el escritor Jorge Amado (1912-2001). La importancia y celebridad públicas de Amado se explican desde sus primeros éxitos editoriales y no es raro que el escritor bahiano se convierta en una constante recurrente en la industria audiovisual brasileña desde finales de los años cuarenta del siglo pasado hasta la actualidad. La obra de Amado transita por algunas líneas temáticas fundamentales del cine brasileño, desde su militancia social hasta la irrupción de esencias que proyectan la exuberancia de un país geográfica y socialmente muy desigual, reducciones, no obstante, de una prosa capital para las letras latinoamericanas y en general, de la literatura universal. Una importancia cifrada también en el cine como muy bien expresa el documental Jorge Amado no cinema (1979) de Glauber Rocha, detallando las relaciones del audiovisual con la obra del escritor bahiano. ${ }^{7}$ El primer largometraje que debe su argumento a Amado es Terra violenta (1948) de Edmond Francis Bernoudy y Paulo Machado a partir de la novela Terras do sem-fim (1943). En los años cincuenta Amado trabajará como guionista y en la década posterior, su célebre novela Gabriela, cravo e canela (1958) se convertirá en una

\footnotetext{
${ }^{7}$ La prosa de Amado ha sido adaptada en países tan distintos como Checoslovaquía (1976) o Egipto (1999), junto al interés que ha despertado la obra del escritor en el cine estadounidense, como manifiestan The Sandpit Generals (1971), singular producción norteamericana de Hal Bartlett, rodada en inglés en Bahía, trasladando Capitães da Areia o Kiss Me Goodbye (1982) de Robert Mulligan, adaptando libremente la novela Dona Flor e seus dois maridos (1966).
} 
serie de televisión de Maurício Sherman (1961). La obra amadiana vivirá sucesivas traslaciones en la televisión y el cine, como la teleserie Gabriela (1975) de Walter Avancini, protagonizada por Sônia Braga, ${ }^{8}$ encarnación de las protagonistas amadianas por antonomasia, inseparable a su nueva interpretación del personaje de Gabriela en el film de Bruno Barreto (1983). Con anterioridad se estrena Seara vermelha (1964) de Alberto D'Aversa, a partir de la novela homónima de 1946, los territorios de la ficción de Amado se ocupan en esta ocasión del sudeste brasileño, concretamente del estado de São Paulo. La trama contiene una profunda crítica social, caracterizando la primera época de la producción literaria del escritor, muy vinculada a su militancia comunista. Desprendida de ese espíritu combativo, pero no de su indisimulada denuncia hacia un sistema injusto y desigual, aparecen las dos traslaciones amadianas de Bruno Barreto que se comentarán más adelante. En sintonía con muchas de las características del Amado más hedonista, se estrena la coproducción francobrasileña Otalia de Bahia (1976), del director francés Marcel Camus, traslación de la novela Os pastores da noite (1964). Concluyendo la década de los ochenta, aparecerá la telenovela Tieta (1989-1990), popularizando aún más en Brasil el imaginario bahiano del escritor, adaptando la novela Tieta do Agreste (1977). ${ }^{9}$ En los noventa se estrena Tereza Batista (1992), teleserie de Paulo Afonso Grisolli, adaptación catódica de Tereza Batista, cansada de guerra (1972). Los ochenta y noventa son años de gran ebullición para el culebrón brasileño, en contraste con la decadencia del cine nacional, ${ }^{10}$ por lo que no es raro encontrar producciones televisivas que toman la prosa de Amado como fuente, títulos como Tocaia Grande (1995-1996) adaptando la novela

\footnotetext{
${ }^{8}$ A partir de un artículo en prensa de Emilia Silveira (1975), Swarnakar (2009) considera que la actriz es una "Gabriela retirante, Gabriela cozinheira de mão cheia, Gabriela flor e mulher foge da imaginação dos milhares de leitores de Jorge Amado para, pela primeira vez, ter um corpo, um rosto, uma voz definitiva, a cores [...] Cada leitor, potencialmente um apaixonado por Gabriela, a imaginava a seu modo, cada admirador do mito da mulher brasileira típica podia ver Gabriela na vizinha, amiga ou mulher. Agora Gabriela tem um nome - Sônia Braga".

${ }^{9}$ Con otra adaptación cinematográfica (1996) de Carlos "Cacá" Diegues.

${ }^{10}$ La progresiva hegemonía de la producción televisiva en las últimas décadas del siglo XX impulsa nuevos modelos de consumo a partir de la telenovela, conquistando los "culebrones" latinoamericanos el mercado internacional (PARANAGUÁ, 1996, p. 382), algo que también afecta al cine brasileño Brasil.
} 
del mismo título (1984) o la teleserie Porto dos Milagres (2001) a partir del texto Mar Morto (1936).

La obra de Amado ha suscitado una enorme atracción para la ficción televisiva brasileña, ${ }^{11}$ pero también es recurrente su proyección en el cine, como demuestran cintas como Quincas Berro d'Água (2010) de Sérgio Machado adaptando A morte e a morte de Quincas Berro d'Água (1959), O Duelo (2015) de Marcos Jorge, inspirado en la novela Os velhos marinheiros ou o capitão de longo curso (1961) e incluso una nueva versión de Dona Flor e seus dois maridos (2017) de Pedro Vasconcelos. En el cine brasileño más reciente se estrena una de las más importantes traslaciones amadianas, se trata del film Capitães da areia (2011), dirigido por Cecilia Amado, nieta del autor bahiano, que materializa por primera vez una traslación al cine nacional de la novela del mismo título de 1937. Un proyecto personal de la directora, que traslada cronológicamente la acción de los años treinta a los años cincuenta en la misma ciudad de Salvador de Bahía, ${ }^{12}$ abordando las sinventuras de una tropa de niños abandonados comandados por Pedro Bala. El grupo vive al margen de la sociedad, aunque cuentan con sus propios códigos de convivencia. La novela está vinculada a una representación de la infancia que se puede rastrear en films latinoamericanos como Los olvidados (1950) de Luis Buñuel, Pixote (1981) de Héctor Babenco, La virgen de los sicarios (2000) de Barbet Schroeder o Cidade de Deus (2002) de Kátia Lund y Fernando Meirelles. El ámbito criminal de la infancia en el que se desarrollan los films citados y la novela de Amado sobrevuela gran parte de la literatura y el cine latinoamericanos a lo largo del siglo XX y se prolonga hasta la actualidad.

\section{Algunos apuntes filmoliterarios del cinema novo}

Tras la colosal producción filmoliteraria de Jorge Amado, aunque su presencia se advertirá con recurrencia, el cine brasileño también se ocupará de otras adaptaciones que vienen delimitadas por la aparición del cinema novo. La constante redefinición del cine brasileño a nivel regional conllevará la aparición de distintas productoras entre las décadas de 1940

\footnotetext{
${ }^{11}$ Interés proyectado en el tiempo como manifiesta la reciente telenovela mexicana Doña Flor y sus dos maridos (2017).

${ }^{12}$ Perteneciente a la primera época de Amado, la novela había contado con la adaptación mencionada de Bartlet (1971) y la libre versión actualizada a los convulsos años ochenta en Salvador de Bahía de la miniserie Capitães da areia (1989) de Walter Lima Jr.
} 
y 1960, empresas como Cinelândia Filmes, Cine-Produções Fenelon Atlântida, la Companhia Cinematográfica Vera Cruz o las efímeras compañias de producción Multifilmes y Cinematografica Maristela (DIEGUES, 1988). En ese constante interludio, la cinematografía nacional de mediados del siglo pasado vive una fase de enorme tecnificación y consolidación industrial. Un contexto fértil para que en la década de 1950 surjan cineastas como Glauber Rocha, Ruy Costa, Joaquim Pedro de Andrade, Leon Hirzsman, Carlos Diegues, Roberto Santos, Roberto Pires, Helena Solberg, Paulo César Saraceni o Nelson Pereira dos Santos. Estos creadores lideran un nuevo cine brasileño, tan heterogéneo como variado, en el que los citados compartían inquietudes artísticas y sociales afines, junto a un antagonismo al cine hollywoodense. Las heterogéneas propuestas del cinema novo se extenderían durante dos décadas y marcarían muchos de los caminos del cine brasileño. No obstante, se estrenarían otros títulos significativos no vinculados con ellos como Presença de Anita (1951) de Ruggero Jacobbi, a partir de la popular novela (1948) de Mario Donato o Arara Vermelha (1957) de Tom Payne, traslación de la novela (1953) de José Mauro de Vasconcelos.

De entre los creadores inscritos en el cinema novo, sobresale la producción filmoliteraria de Nelson Pereira dos Santos, primero dentro de las corrientes renovadoras de cine brasileño y posteriormente consolidado adaptador de textos literarios. En 1963, el director paulista estrena Vidas secas (1963), trasvase de la novela naturalista de tema rural (1938) de Graciliano Ramos, ${ }^{13}$ la película se desarrolla en el rudo sertão del nordeste brasileño. En la década de 1960, Pereira dos Santos dirige la comedia satírica en El Justicero (1967), film que será objeto de la censura de la dictadura militar brasileña (1964-1985), inspirado por As vidas de El Justicero: O Cafajeste sem medo e sem mácula (1965) de João Bethencourt. A pesar de estas dificultades, el director puede estrenar sus siguientes largometrajes a partir de textos literarios como Fome de Amor (1968), a partir de la novela História para se ouvir de noite (1964) de Guilherme Figueiredo; Azyllo muito louco (1970) basada en el cuento

\footnotetext{
${ }^{13}$ La obra de Graciliano Ramos ha sido objeto de traslaciones filmoliterarias como São Bernardo (1972) de Leon Hirszman y el propio Pereira dos Santos realiza Memórias do cárcere (1984), memorias carcelarias de Ramos, publicadas póstumamente en 1953, el escritor estuvo encarcelado por ser militante comunista en los años treinta.
} 
"O alienista" (1882) de Machado de Assis ${ }^{14}$ y Quem é Beta? (1972), trasvasando el relato "O último artilheiro" (1965) de Levi Menezes.

En las postrimerías de los setenta, Pereira dos Santos traslada la novela Tenda dos Milagres (1969) ${ }^{15}$ de Jorge Amado, estrenándose el film en 1977, retornando a los espacios bahianos de principios del siglo pasado. Un interés en el universo del escritor que el director retoma en Jubiabá (1986), novela (1935) y film se ambientan en Salvador de Bahía, urbe amadiana por excelencia, el relato está imbuido por la militancia de izquierdas del escritor de Itabuna. El colofón filmoliterario de Pereira dos Santos es A terceira margem do rio (1994), ambientado en el sertão, tomando como base el libro Primeiras estórias (1962) de João Guimarães Rosa. ${ }^{16}$

Volviendo al punto de partida que arranca con el cinema novo, éste va a marcar las exploraciones y los caminos del cine brasileño, pero además se va a erigir en vehículo para popularizar y travasar textos fundamentales de la literatura nacional. Tras la prolífica producción de Pereira dos Santos sobresalen, por su número e importancia, las adaptaciones del escritor Machado de Assis. En las intersecciones del romanticismo y el realismo, el novelista carioca vivirá un proceso de reconocimiento a partir de la década de 1960 por parte del cine similar a lo ocurrido con la prosa de José de Alencar durante el cine silente. El film capitular Esse Rio que eи ато (1962) del realizador argentino Carlos

\footnotetext{
${ }^{14}$ Como luego se apuntará, el escritor Joaquim Maria Machado de Assis (1839-1908) resulta fundamental para entender las tendencias de la traslación filmoliteraria en Brasil a partir de 1960.

${ }^{15}$ La novela fue adaptada en serie televisiva en 1985 para la Rede Globo de televisão.

${ }^{16} \mathrm{La}$ obra de Guimarães Rosa, próxima al realismo mágico, ofreció una gran capacidad de seducción para el cine brasileño. Destacando films como Grande Sertão: veredas (1965) de Geraldo y Renato Santos Pereira, Sagarana, o Duelo (1974) de Paulo Thiago o A hora e a vez de Augusto Matraga (2011) de Vinícius Coimbra. De este relato, existe otra destacable versión, A hora e vez de Augusto Matraga (1965) de Roberto Santos, film marcado por la polémica contra la exhibición de la película por parte de la familia del escritor y que mantiene un diálogo sugerente con los filmes de sertão del cinema novo (Nogueira Galvão, 2006). El interés del audiovisual por el escritor de Minas Gerais se extiende a Cabaret Mineiro (1980) de Carlos Alberto Prates Correa y Noites do Sertão (1984) a partir de los relatos de "Soroco, Sua Mãe, Sua Filha" (1962) y "Buriti" (1956) respectivamente o la más reciente Mutum (2007) de Sandra Kogut sobre la novela Campo Geral (1964).
} 
Hugo Christensen, ${ }^{17}$ partiendo de los relatos "Balbino, o homem do mar" y "O milhar seco" (1960) de Orígenes Lessa; junto a los cuentos "A morte da porta-estandarte" de Aníbal Machado y "Noite de Almirante" (1873) de Machado de Assis, marcará una inflexión en las sucesivas traslaciones de Machado de Assis, como Viagem ao fim do mundo (1968) de Fernando Campos a partir de Memórias póstumas de Brás Cubas $(1881)^{18} \mathrm{o}$ Capitu (1969) del director Paulo César Saraceni e inspirada en la novela Dom Casmurro (1899). ${ }^{19}$ En la década subsiguiente, Machado de Assis vuelve a interesar en películas como Um homem célebre (1974) de Miguel Faria Jr., A Cartomante (1974) de Marcos Farias, Confissões de uma viúva moça (1976) de Adnor Pitanga, basados en los cuentos del mismo título del escritor brasileño. Además, cada cierto tiempo la industria audiovisual brasileña se ocupa de recurrir al autor: Que estranha forma de amar (1977) de Gerardo Vietri a partir de la novela Iaiá Garcia (1878); Quincas Borba (1987) de Roberto Santos sobre la novela del mismo título (1891); y las traslaciones del cuento "A Causa Secreta" (1896): A causa secreta (1994) de Sergio Bianchi y A erva do rato (2008) de Júlio Bressane. Esta enumeración de traslaciones de Machado de Assis, sin valorar su importante impacto en las series de televisión, evidencia la importancia del escritor en el audiovisual brasileño.

En este periplo, por la idiosincrasia de las traslaciones filmoliterarias en Brasil, aparece la figura de Nelson Rodrigues, novelista, dramaturgo y guionista pernambucano, que ofrece un amplio inventario de títulos que se extiende a lo largo de más de seis décadas del audiovisual brasileño: Meu destino é pecar (1952) de Manuel Peluffo, adaptación de la novela del mismo título (1944), Asfalto selvagem (1964) y Engraçadinha Depois dos Trinta (1966) de J. B. Tanko que, junto a Engraçadinha (1981) de Haroldo Marinho Barbosa, parten de la misma novela de Rodrigues, Asfalto selvagem: Engraçadinha, seus pecados e seus amores (1959); $O$ casamento (1976) de Arnaldo Jabor sobre la novela homónima (1966) y

\footnotetext{
${ }^{17}$ El competente Christensen se convertirá en uno de los realizadores nómadas más importantes del cine de Iberoamérica, destacando además por otra traslación brasileña en O menino e o vento (1967), film inspirado en el cuento "O iniciado do vento" (1959) de Aníbal Machado.

${ }^{18}$ Novela adaptada de nuevo al cine en Brás Cubas (1985) de Júlio Bressane y en la coproducción lusobrasileña Memórias póstumas (2001) de André Klotzel.

${ }^{19}$ Moacyr Goés estrena Dom (2003), libérrima versión del texto de Machado de Assis.
} 
Gêmeas (1999), debut en la dirección de Andrucha Waddington, uno de los últimos talentos salidos del cine brasileño, inspirándose en el cuento "As gêmeas" (1992).

El exotismo o las inquietudes de la literatura modernista se reflejarían luego en las cintas más destacadas de Joaquim Pedro de Andrade, que dirigirá $O$ padre e a moça (1966), a partir de un texto poético de Carlos Drummond de Andrade; la multicultural Macunaíma (1969), sobre la novela (1928) del mismo título escrita por Mário de Andrade; Cleo e Daniel (1970) de Roberto Freire, adaptando su propio libro (1965), cercano al psicoanálisis de Wilhelm Reich; As confissões de Frei Abóbora (1971) de Braz Chediak y Rua descalça (1971) de J. B. Tanko, basadas en la novelas del mismo título de José Mauro de Vasconcelos; O pica-pau amarelo (1973) de Geraldo Sarno sobre la novela (1939) de Monteiro Lobato; Um certo Capitão Rodrigo (1971) de Anselmo Duarte, inspirada por la trilogía literaria $O$ tempo e o vento de Érico Veríssimo; Já não se faz amor como antigamente (1976) de Anselmo Duarte, John Herbert y Adriano Stuart, película episódica dentro del subgénero cómico de la "pornochanchada" 20 inspirada en un texto de Lygia Fagundes Telles; Antônio Conselheiro e a Guerra dos Pelados (1977) de Guga de Oliveira, basada en la novela Os sertões (1902) de Euclides da Cunha; As três mortes de Solano (1978) de Roberto Santos partiendo del cuento $A$ Caçada (1965) de Lygia Fagundes Telles; República dos assassinos (1979) de Miguel Faria Jr. a partir del libro de Aguinaldo Silva; y la novela $O$ coronel e o lobisomem (1970) de José Cândido de Carvalho, que cuenta, además, con otras dos versiones en cine e idéntico título dirigidas por Alcino Diniza (1979) y Maurício Farias (2005) que ambientan esta trama picaresca a comienzos del siglo XX en el enfrentamiento con los atávicos resabios de una sociedad ultraconservadora y patriarcal que se resiste a caer con evocaciones al realismo mágico.

\footnotetext{
${ }^{20} \mathrm{Al}$ dar sus últimos estertores la dictadura militar y la relajación de su vigilancia social, favoreció la aparición la pornochanchada, subgénero emparentado con el "landismo" y el llamado cine español del destape, las comedias eróticas argentinas de Armando Bó protagonizadas por Isabel Sarli o incluso con la "sexycomedia" mexicana. Conviene revisar a Nuno C. Abreu en Ramos y Miranda (2004, p. 431-433).
} 


\section{La seducción del cine brasileño en las pantallas internacionales}

La relevancia para la industria de escritores tan diversos como los señalados, permite detenerse en una figura capital para entender el cine brasileño tras el cinema novo. El director Bruno Barreto entendió pronto la necesidad de hacer un cine con vocación de autor, pero con aspiraciones comerciales y una distribución internacional que pusiera en el mapa al cine nacional, específicamente que posicionase el cine de Barreto como el cine brasileño. Para esa tarea se encomendó a una asociación de éxito casi infalible, recurrir a dos novelas fundamentales de Jorge Amado. Barreto contó primero con el soporte de sus padres, productores cinematográficos, para hacerse un nombre en la industria. Siendo un bisoño veinteañero estrenaría producciones de factura correcta que cuentan con el favor del público y que beben de la literatura y de la música brasileñas como principales inspiraciones. Con dieciocho años estrena Tati (1973), drama sobre una madre soltera que se basa en el cuento "Tati, a Garota" de Aníbal Machado y luego llegaran A estrela sobe (1974) a partir de la novela realista (1939) del escritor Marques Rebelo; y las exitosas traslaciones de las novelas de Amado, Dona Flor e seus dois maridos (1976) ${ }^{21}$ y Gabriela, cravo e canela (1983), que se convierten en el díptico bahiano del cineasta. Las dos películas le proporcionan éxito y reconocimiento internacional. Además, Barreto logra un posicionamiento dentro de la industria norteamericana como demuestran O que é isso, companheiro? (1997), coproducción brasileiroestadounidense, recreando el secuestro por guerrilleros del embajador de EE.UU. en el Brasil de finales de los sesenta durante la dictadura militar e inspirado en el libro del mismo título del político, periodista y escritor Fernando Gabeira. Siguiendo esta fórmula de coproducción Barreto estrena Bossa Nova (2000), inspirado en el cuento "A Senhorita Simpson" de Sérgio Sant'Anna. Estas incursiones no obtienen el éxito comercial esperado y Barreto prosigue su carrera con films más pequeños como O casamento de Romeu e Julieta (2005), trama shakesperiana que adapta la novela breve Palmeiras: um caso de amor de Mário Prata y Flores raras (2013) basada en el libro Flores raras e banalíssimas de la escritora Carmen L. Oliveira.

\footnotetext{
${ }^{21}$ Evidenciando el éxito del film, cuenta con la pornochanchada Seu Florindo e suas duas mulheres (1978) de Mozael Silveira.
} 
El cine brasileño de los ochenta y de décadas posteriores contará también con otro Barreto, Fábio Barreto, hermano de Bruno, y que buscará el éxito con una carrera irregular llena de propuestas que alternan temas que explotan el exotismo tópico asociado a Brasil o historias de época, títulos que son traslaciones literarias que van desde Índia, a filha do Sol (1982) a partir del cuento de Bernardo Élis; Luzia Homem (1988) sobre la novela naturalista de Domingos Olímpio; O quatrilho (1995) basada en el libro homónimo de José Clemente Pozenato; Bela Donna (1998) coproducción brasileña con EE.UU. que adapta la novela modernista Riacho doce de José Lins do Rego y A paixão de Jacobina (2002), traslación de la novela Videiras de cristal de Luiz Antônio de Assis Brasil.

En este zizagueante recorrido, retomando la última etapa de la dictadura militar, hay que destacar a uno de los creadores clave del cine brasileño de las últimas cuatro décadas, Héctor Babenco, director argentino naturalizado brasileño que sobresale con Pixote: a lei do mais fraco (1981), acerada denuncia de una juventud abocada a la delincuencia y la droga, películas que como otras de la época, y con temas similares a los del cine latinoamericano de la pornomiseria, aspiraban a contar mucho más sin las pretensiones comerciales de otras propuestas que se regodeaban en la violencia y en las imágenes de las penurias que podía ofrecer la región. El film de Babenco muestra una infancia y una juventud cuyas oportunidades sin porvenir pasaban por transgredir leyes y normas sociales en las grandes ciudades de América Latina. Todo ello se recoge en el libro que inspira la película, $A$ infância dos mortos de José Louzeiro, co-guionista del film, sobre un niño obligado a delinquir por las circunstancias de un sistema que no le ofrece alternativas ni educativas ni económicas para sobrevivir o subsistir. La conclusión de la dictadura coincide casi en el tiempo con el estreno de Kiss of the Spider Woman (O beijo da mulher-aranha, 1985), coproducción entre Brasil y Estados Unidos dirigida por Babenco. La película es la traslación parcial de la novela El beso de la mujer araña (1976) del escritor argentino Manuel Puig, rodada fundamentalmente en inglés, se convierte en uno de los grandes triunfos internacionales del cine brasileño, abordando el tema de la tortura, la represión y la anulación de cualquier disidencia cifrada en lo ideológico y en lo sexual por parte de las dictaduras latinoamericanas. El éxito de la película permite a Babenco compaginar su trabajo en la industria estadounidense y en producciones nacionales durante las 
décadas posteriores, alternando films como At Play in the Fields of the Lord (Brincando nos Campos do Senhor, 1991), coproducción entre Brasil y EE.UU., a partir de la novela (1966) de Peter Matthiessen o el destacado regreso del director al ámbito de la marginalidad, la cárcel y la represión en Carandiru (2003), film basado en Estação Carandiru (1999) de Dráuzio Varella, libro que recrea la masacre de centenares de presos ocurrida el 2 de octubre de 1992 en la penitenciaría Carandiru por la violenta y desmedida intervención de la Policía Militar en el estado de São Paulo tras un motín de reclusos.

Después de la secuencia sintetizada de los principales realizadores brasileños de la segunda mitad del siglo XX y conformada por Rocha, Pereira dos Santos, Barreto y Babenco, aparecería en este "panteón" la figura de Walter Salles, que sirve de enlace con el llamado cine brasileño del período conocido como Retomada desde 1992 (ORICCHIO, 2003). El interés que despierta la producción de Salles en el mundo surge tras un debut prometedor, un film de vocación transnacional, pero de tema brasileño, se trata de la cinta A Grande Arte (1991), coproducción Brasil-EE.UU. rodada en inglés en escenarios brasileños con un elenco internacional. La película adapta la novela homónima del escritor brasileño Rubem Fonseca ${ }^{22}$ y es un notable ejemplo del cine noir latinoamericano, que tan buenos títulos dará a lo largo de los últimos decenios. Después de su incursión en el cine de género, Salles se centra en un cine social, denunciando situaciones como la soledad, el desarraigo, la pobreza, la desprotección de la infancia o el tráfico de personas en films con guiones originales como Terra estrangeira (1995), codirigido por Daniela Thomas o Central do Brasil (1998). En el siglo XXI, Salles

\footnotetext{
${ }^{22}$ Fonseca, una de las plumas más brillantes de la literatura brasileña desde hace décadas, ha contado con el interés de Salles o Paul Leduc para trasladar sus historias de descarnada denuncia social o su cruda mostración de la condición humana. La prosa del escritor ha encontrado su lugar en el cine y en la televisión como demuestran los films Lúcia McCartney, uma garota de programa (David Neves, 1971), Relatório de um homem casado (1974) basada en "Relatório de Carlos" o A extorsão (1975), ambas de Flávio Tambellini. También $O$ Caso Morel (Sheila Feital, 2006) traslación de la primera novela del escritor o el film portugués Axilas (José Fonseca e Costa, 2016) inspirada en cuentos del libro Axilas e outras histórias indecorosas. En muchas de ellas el propio Fonseca ejerce de guionista, incluso con material ajeno como $O$ homem do ano (2003), debut del director José Henrique Fonseca, hijo del escritor, a partir de la novela negra $O$ matador (1995) de Patricia Melo.
} 
estrena Abril despedaçado (2001) a partir de la novela albanesa Prilli $i$ Thyer del escritor Ismail Kadare, ambientando esta historia de violencia rural a principios del siglo XX en localizaciones de Bahía. El director rueda después en español, y con el auspicio del cineasta Robert Redford, adaptación de Notas de viaje, el diario de Ernesto Che Guevara y Con el Che por Sudamérica, el libro de Alberto Granado, compañero de viaje del futuro guerrillero y político argentino en su itinerario sudamericano a principios de los cincuenta. El film, coproducción entre Brasil, Argentina, Chile, EE.UU., Perú, Reino Unido, Alemania y Francia, se estrena como Diários de motocicleta (2004), obteniendo una gran recepción de crítica y público en las pantallas de todo el mundo. A partir de ese momento, Salles se centra en films de producción estadounidense en los que adapta a autores como Jack Kerouac o Kōji Suzuki.

El periodo comprendido entre los años noventa del siglo pasado y principios del siglo XXI, el cine brasileño compagina la coproducción con capitales europeos o estadounidenses con la financiación nacional, los cineastas de la Retomada consolidan una etapa de gran ebullición tras las dificultades de las últimas décadas del siglo pasado. Las traslaciones filmoliterarias Lili, a estrela do crime (1989) de Lui Farias, a partir del cuento "Lili Carabina" de Aguinaldo Silva; la coproducción con EE.UU. O quinto macaco (1990) de Éric Rochat sobre la novela de Jacques Zibi; As meninas (1995) de Emiliano Ribeiro, traslación de la novela de Lygia Fagundes Telles; Guerra de Canudos (1997) de Sergio Rezende, basada en la novela de Euclides da Cunha; los Contos de Lygia (1998) del director Del Rangel sobre relatos de nuevo de Fagundes Telles; y Um copo de cólera (1999) de Aluizio Abranches y Lavoura arcaica (2001) de Luiz Fernando Carvalho, ambas adaptaciones de novelas del escritor paulista Raduan Nassar, conforman un corpus que da cabida a una línea continuista dentro de las inquietudes y autores adaptados con anterioridad.

En el cambio de siglo el cine de género brasileño cuenta con una destacada generación de creadores, sobresaliendo en este ámbito la alianza del escritor Marçal Aquino y el director Beto Brant. Os matadores (1997), basado en el cuento homónimo de Marçal Aquino, supone el debut en el largometraje de Brant. Posteriormente, Brant dirige Ação entre amigos (1998), una historia ambientada en la dictadura cuyo argumento original es de Aquino, siendo éste uno de los responsables del guión. El estreno de O invasor (2001), dirigida por Brant, indica la buena salud de su alianza con Aquino, que firma el guión a partir de una novela inédita, 
que se publicará después. $O$ invasor presenta los mejores ingredientes del thriller de inspiración hitchcockiana, con una trama en la que un personaje externo, un sociópata, cambia completamente la situación de un grupo de personajes de clase alta implicados en un crimen con móvil económico y profundos dilemas morales. Aquino y Brant prosiguen su relación en Crime delicado (2005), película dirigida por el segundo a partir de la novela Um crime delicado de Sérgio Sant'Anna y que se ocupa de adaptar Aquino, que vuelve a ser el responsable del libreto de Cão sem dono (2007), codirigida por Brant y Renato Ciasca, adaptación de la novela Até o dia em que o cão morreu de Daniel Galera. Sin la colaboración de Brant se estrena Cabeça a prêmio (2009) de Marco Ricca, basada en la novela del mismo título de Aquino. La colaboración de Aquino y Brant se retoma en O Amor segundo B. Schianberg (2010), sobre Benjamin Schianberg, personaje que el director toma del libro Eu receberia as piores notícias dos seus lindos lábios, a su vez novela convertida en film en 2011, y de nuevo codirigida por Brant y Ciasca con la participación de Aquino en la escritura de la película, por ahora es la última colaboración en una obra de ficción entre Brant y Aquino, volcado el escritor en la última década en la creación literaria y en la producción televisiva.

A principios del siglo XXI se produce un fenómeno de proporciones sísmicas con el estreno y la distribución de una coproducción brasileña con participación francesa y alemana. El cine brasileño reciente tiene su carta de presentación más apabullante con Cidade de Deus (2002) de Kátia Lund y Fernando Meirelles, la cinta se va a situar como uno de uno de los films más vistos de la temporada 2002-2003 en todo el mundo y se erige, por derecho propio, en un testimonio tan cruento como sincero de la juventud y la marginalidad en cualquier suburbio de una gran urbe latinoamericana. La película fue víctima de críticas similares a las que sufrió Buñuel tras el estreno mexicano de Los olvidados, situando al film brasileño en los espacios y los personajes de infancias y juventudes marginales que se configuran como un retrato crudo y violento del espacio suburbial latinoamericano del pasado y del presente de la región. Tras la expectación de la carrera de Salles, Cidade de Deus constituye un éxito sin precedentes del cine brasileño en el mercado internacional, convirtiéndose en una de las adaptaciones literarias más exitosas de la historia del cine en general y del cine latinoamericano en particular. El film adapta Cidade de Deus (1997), novela del escritor Paulo Lins, con 
ecos próximos a la multiplicidad coral y cruzada de Manhattan Transfer de John dos Passos, aunque las coincidencias narrativas o el ámbito urbano de una y otra están claramente distanciados. La novela de Lins está abarrotada de los personajes que viven en las favelas cariocas que pueblan los suburbios y la periferia de las grandes ciudades del mundo, sea en los países subdesarrollados o en los límites urbanos del llamado hemisferio occidental. A pesar de lo inabarcable del texto literario, el guionista Bráulio Mantovani supo epatar con un libreto que merecería estudiarse en cualquier escuela que aspire a formar guionistas en materia de adaptación. El memorable trabajo de actores es una de las mayores responsabilidades de la notable documentalista Kátia Lund, ${ }^{23}$ codirectora del film, La carrera del director paulista podría haber sido más regular, pero algunas de sus elecciones para dirigir, tras la crónica histórica ambientada en las infraviviendas de Río de Janeiro, han demostrado su acierto para llevar a la pantalla otros textos literarios. Meirelles es el responsable de films como The Constant Gardener (2005), coproducción ${ }^{24}$ entre Reino Unido, Alemania, EE.UU., China y Kenya, que se desarrolla en gran parte en el país africano, mostrando el poder del sector farmacéutico y su influencia en el desarrollo humano de cualquier país. Posteriormente, Meirelles vuelve a rodar en inglés Blindness (Ensaio sobre a cegueira, 2008), coproducción brasileña con Canadá y Japón que asume la difícil tarea de materializar la traslación de Ensaio sobre a cegueira (1995), novela distópica firmada por el Nobel portugués José Saramago y recientemente ha estrenado la coproducción internacional The Two Popes (2019) centrado en la relación de los pontifices católicos Benedicto XVI y Francisco a partir de un texto original de Anthony McCarten.

José Padilha, compartiendo generación con Meirelles y Brant, presenta una proyección internacional que le ha convertido en un demandado director de acción. Su reputación profesional se debe a su pericia en producciones con un enorme trasfondo social, destacando los films Tropa de Elite (2007) y su secuela Tropa de Elite 2 (2010), películas que adaptan los libros Elite da Tropa, escrito por los policías André Batista y Rodrigo Pimentel junto al antropólogo Luiz Eduardo Soares $y$

\footnotetext{
${ }^{23}$ Un trabajo actoral en el que destaca Fátima Toledo, la acting coach o preparadora de elenco que se hizo célebre tras la película de Meirelles y Lund, cuya trayectoria y aplicación en el cine brasileño arranca brillantemente en Pixote, siendo demandada por algunas de las más importantes cintas del cine brasileño reciente (CARDOSO, 2014). ${ }^{24}$ El film trasvasa el thriller político del mismo título del escritor británico John Le Carré.
} 
Elite da Tropa 2: O inimigo agora é outro, también de Batista, Pimentel y Soares con la participación de Cláudio Ferraz. Los dos largometrajes obtuvieron un gran recorrido en las pantallas del mercado internacional, apuntando la línea ascendente que el cine brasileño ha tenido tras la irrupción de Cidade de Deus.

En las dos últimas décadas han aparecido otras traslaciones del cine brasileño como Bicho de sete cabeças (2000) de Laís Bodanzky, a partir del libro de Austregésilo Carrano; O Xangô de Baker Street (2001) de Miguel Faria Jr., traslación de la novela homónima de Jô Soares que recurre a las peripecias en Río de Janeiro del detective Sherlock Holmes, creado a su vez por Arthur Conan Doyle; O cheiro do ralo (2007) de Heitor Dhalia, sobre la novela de Lourenço Mutarelli; Um romance de geração (2008) de David França Mendes, a partir del libro de Sérgio Sant'Anna; Meu pé de laranja lima (2012) de Marcos Bernstein, basado en la novela $O$ meu pé de laranja lima de José Mauro de Vasconcelos; Prova de coragem (2015) de Roberto Gervitz, adaptación de Mãos de Cavalo de Daniel Galera, O silêncio do Céu (2016) de Marco Dutra a partir de la novela Era el cielo de Sergio Bizzio o Entre hermanas (2017) de Breno Silveira, traslación de la novela de la escritora Frances de Pontes Peebles, nacida en Recife y criada en Estados Unidos, caso que comparte similitudes con muchos narradores latinoamericanos actuales. Todos estos ejemplos de una u otra manera muestran la diversidad de propuestas del cine brasileño.

Para refrendar lo apuntado al principio, el interés de la producción filmoliteraria de Brasil respecto a otras culturas latinoamericanas se materializa en diferentes producciones brasileñas o en largometrajes cuyos mayores responsables son cineastas brasileños. De esta forma, podemos encontrar el vínculo creativo del director Ruy Guerra con el universo ficcional de Gabriel García Márquez, colaborando con el escritor colombiano en títulos como Eréndira (1983), coproducción mexicana con Francia y Alemania que adapta la novela corta La increíble y triste historia de la cándida Eréndira y de su abuela desalmada. Además, en Brasil, Guerra dirige la coproducción hispanobrasileña Fábula de la Bella Palomera (1988) sobre libreto del escritor colombiano y en 2005 estrena $O$ veneno da madrugada (2005), traslación de La mala hora, tercera novela de García Márquez. Otro ejemplo de esa mirada brasileña a las narrativas hispanoamericanas es Inesquecivel (2007) de Paulo Sérgio de Almeida, basada en el cuento "El Espectro" de Horacio Quiroga y 
más recientemente, el cineasta brasileño Selton Mello dirige $O$ filme da minha vida (2017), largometraje inspirado en Un padre de película, novela del autor chileno Antonio Skármeta, trasladando la acción desde Contulmo, en la provincia chilena de Arauco, a Rio Grande do Sul; del sur chileno al sur brasileño junto a otros desplazamientos tan interesantes como el diverso y variado conjunto que amalgama el cine brasileño y el elenco internacional de la cinta, evidenciando las intersecciones en las que integrar tanto el estudio como las posibilidades del cine brasileño en los territorios de América Latina, que lejos de ser una ínsula varada, es un territorio tan firme como las oportunidades en el porvenir del audiovisual de la región.

\section{Una cierta mirada, un espacio común: el cine brasileño en la encrucijada latinoamericana}

Los ensayos de Octavio Getino $(1988,2007)$ siguen manteniendo una vigencia mayúscula en el análisis industrial del cine latinoamericano, acudiendo además a los últimos informes anuales de los productores iberoamericanos ${ }^{25}$ se puede apreciar la situación del cine de la región en su conjunto y en el contexto transnacional junto a la presencia actual del cine vernáculo en las pantallas brasileñas y en las del resto de los países iberoamericanos. En el prontuario de desdichas compartidas, el cine brasileño ha sufrido los mismos avatares y la misma desidia por parte de legisladores y gestores políticos que el resto de los cines latinoamericanos.

La voluntad del estudio de integrar una visión amplia está motivada por el objetivo de ofrecer una perspectiva sucinta de la traslación filmoliteraria en el cine brasileño, orientada fundamentalmente a contar con un panorama lo suficientemente variado con el que poder analizar tendencias comunes con el audiovisual latinoamericano. La limitación de elegir un tipo determinado de producciones, las que privilegian el origen de los films a partir de textos literarios, es una circunstancia análoga a los procesos creativos e industriales de otras cinematografías de la región. Esta selección ha eludido películas con guión original y de gran relevancia para el cine brasileño, por cuestiones operacionales se ha prescindido de

\footnotetext{
${ }^{25}$ EGEDA $(2018,2019)$, informes útiles para entender la situación industrial, las cuotas de pantalla y el impacto del cine iberoamericano.
} 
títulos fundamentales de la cinematografía brasileña, omisión razonada y justificada por los intereses del trabajo y que se pueden apreciar en la escasa presencia de un autor tan influyente y fundamental como Glauber Rocha, algo motivado porque sus principales films partieron de guiones propios o ajenos que no partían de un texto literario.

En este viaje intermedial por la literatura y el cine brasileños, plagado de idas y venidas, es obligado atender a la enorme producción audiovisual, la cercanía geográfica, la afinidad cultural y la imprescindible aproximación de los productos culturales brasileños para toda América Latina. Este acercamiento debe ser prioritario para creadores, gestores culturales, empresarios, productores cinematográficos y responsables políticos. Difícilmente la región puede perpetuar este olvido más tiempo, cuyos factores principales son la barrera lingüística y los intereses comerciales de las corporaciones multinacionales. En el siglo XXI no se puede entender América Latina sin más de doscientos millones de brasileños y una producción audiovisual tan fértil como sugerente.

\section{Referencias}

BRASIL. Ministério de Educação. Lei n. 11.161, de 5 de agosto de 2005. Dispõe sobre o ensino da língua española. Brasília, DF: Diário Oficial da União, 2005. Disponible en: http://legislacao.planalto.gov.br/legisla/ legislacao.nsf/Viw_Identificacao/lei\% 2011.161-2005?OpenDocument. Acceso el: 20 dic. $\overline{2019 .}$

CARDOSO, Maurício. Fátima Toledo: interpretar a vida, viver o cinema. São Paulo: Editora Liber Ars, 2014.

DIEGUES, Carlos. Cinema brasileiro: Idéias e imagens. Porto Alegre: Editor da Universidade, 1988.

EGEDA(Entidad de Gestión de Derechos de los Productores Audiovisuales). Panorama Audiovisual Iberoamericano 2018. 2018. Disponible en: https://www.egeda.es/EGE_LibrosPanoramaIberoamericano2018.asp. Acceso el: 6 ene. 2020.

EGEDA(Entidad de Gestión de Derechos de los Productores Audiovisuales). Panorama Audiovisual Iberoamericano 2019. 2019 Disponible en: https://www.egeda.es/EGE_LibrosPanoramaIberoamericano2019.asp. Acceso el: 6 ene. 2020. 
ELENA, Alberto. Los cines periféricos: África, Oriente Medio, India. Barcelona: Paidós, 1999.

GETINO, Octavio. Cine latinoamericano: economía y nuevas tecnologías audiovisuales. Buenos Aires: Legasa, 1988.

GETINO, Octavio. Cine Iberoamericano: los desafíos del nuevo siglo. Buenos Aires: Ediciones Ciccus, 2007.

NOGUEIRA GALVÃO, Walnice. Metamorfoses do Sertão (literatura, canção, cinema). Caravelle: Cahiers du Monde Hispanique et LusoBrésilien, Toulouse, n. 86, p. 193-213, 2006. DOI: https://doi.org/10.3406/ carav.2006.2927

ORICCHIO, Luiz Zanin. Cinema de novo. Um balanço crítico da retomada. São Paulo: Estação Liberdade, 2003.

PARANAGUÁ, Paulo Antonio. América Latina busca su imagen. In: HEREDERO, Carlos F.; TORREIRO, Casimiro (coord.). Historia General del cine: Estados Unidos (1955-1975) y América Latina. Madrid: Cátedra, 1996. p. 207-383. v. X.

RAMOS, Fernão; MIRANDA, Luiz Felipe (ed.). Enciclópedia do cinema brasileiro. Paulo: Senac, 2004.

SALES ARAUJO, Naiara. Brazilian and Spanish Literature and Cinema: A Comparative Perspective. Publicaciones, Granada, v. 48, n. 2, p. 347358, 2018. DOI: https//:doi.org.10.30827/publicaciones.v48i2.8349.

SILVEIRA, Emilia. O cheiro de cravo, a cor de canela, eu vim de longe, vim ver Gabriela. Jornal do Brasil, Rio de Janeiro, 13 abr. 1975.

SWARNAKAR, Sudha. Filmic Adaptation of Amado's Gabriela: Distorting the Theme. In: LATINAMERICAN STUDIESASSOCIATION (LASA). INTERNATIONAL CONGRESS, XXVIII., 2009, Rio de Janeiro. Proceedings [...]. Rio de Janeiro: LASA; PUC-Rio, 2009. v. 1, p. 1-13. 